\title{
EFFECT OF SWIMMING AND PHYSIOTHERAPY IN PATIENTS WITH NEPHROLITHIASIS
}

\section{Nikolay Izov ${ }^{1}$, Ivan Maznev ${ }^{1}$, Milena Nikolova ${ }^{1}$, Dance Vasileva ${ }^{2}$}

${ }^{1}$ National Sports Academy, Sofia, Bulgaria, ${ }^{2}$ Faculty of Medical Sciences, GoceDelchev University, Shtip, Republic of Macedonia

\begin{abstract}
Aim: This research aims to evaluate the effect of swimming and physiotherapy in a complex treatment of patients with nephrolithiasis treated under sanatorium conditions.

Materials and methods: Twenty patients with nephrolithiasis who can swim, were surveyed and all of them were included in the experimental group $(E G n=20)$. They performed swimming and physical therapy. Mean age of EG was 44.1 years. Swimming was not applied to another twenty-eight patients with the same disease, because they cannot swim. They were included in the control group $(C G n=28)$. Mean age of $C G$ was 49.5 years. For the purpose of the research changes in: body weight, vital capacity, abdominal muscle strength and elimination of the concretions visualized by ultrasound imaging were assessed. During their 15-day sanatorium stay, all patients performed daily physiotherapy for half an hour, tourist hikes and in addition patients of EG swam twice daily for $15 \mathrm{~min}$.

Results: The results revealed that the applied physiotherapy and swimming signifcantly improved the monitored indicators. Targeted physical exercises were effective for increasing the effect of balneological treatment, leading to clearly expressed positive changes among patients with nephrolithiasis.
\end{abstract}

Conclusion: The study revealed that the rehabilitation program consisting of therapeutic exercises and swimming benefited the patients of the experimental group.

Keywords: nephrolithiasis, swimming, physiotherapy, SPA, balneology 


\section{INTRODUCTION}

Nephrolithiasis is a common disease and represents about $40 \%$ of the patients in urological clinics. Bulgaria is among the countries where it is widespread. By its importance, nephrolithiasis is not only a health problem, but also a social problem. Complex balneotherapy plays an important role in solving therapeutic problems of patients with nephrolithiasis and includes: medication, drinking mineral water, physiotherapy, swimming, SPA, underwater jet massage, fangotherapy (mineral-laden mud), lye saltwort-therapy, a vibrating belt, diet, and climatotherapy. Swimming and physiotherapy take an important place among the other methods in the complex treatment of patients with nephrolithiasis, both under balneo-sanatorial conditions, where medical results are optimal, and in terms of ambulant treatment and preventing kidney stone formation. The main goal of this study was to evaluate the effect of physiotherapeutic methods in complex treatment of patients with nephrolithiasis under sanatorium conditions.

\section{MATERIALS AND METHODS}

This research was conducted in "Kaleroya" in the town of Hissar, where twenty patients with nephrolithiasis were surveyed. Their mean age was 44.1 years (30-59) and all of them were included in the experimental group (EG) which performed swimming a nd therapeutic exercise sessions. Swimming was not applied to another twenty-eight patients with the same disease, who refused to swim. They were included in the control group (CG) who participated in the physical therapy sessions, their mean age was 49.5 years (36-60). All patients from EG and CG were on standard analgesic and antispasmolitic medication, that included the following medicaments: papaverine, atropine, santropine, spasmalgon, buscolysin and no-spa. In addition, drinking mineral water, in adequate intake, was administered to all patients of both groups (daily drinking mineral water from the spring "Momina banya" in amount 1500 $\mathrm{ml}-1800 \mathrm{ml}$, divided in 5-6 portions. The last portion was taken later, just before bedtime and even at night), water strikes twice a week, underwater jet massage and hydrotherapy (water temperature: $37^{\circ} \mathrm{C}$ $38^{\circ} \mathrm{C}$, duration of the procedure: from 5 to $15-18 \mathrm{~min}$ ); fangotherapy or saltworttherapy, a vibrating belt, and a diet.

Before starting the research and after its completion, in both groups changes were monitored in: body weight, strength of abdominal muscles, forced vital capacity and elimination of a concretion, which was visualized by ultrasound imaging and anamnestic.

Body weight was monitored by a medical scale with precision 50 gr, supports weight of $200 \mathrm{~kg}$ with standard method.

To assess the strength of abdominal muscles we used one of the test positions from the static part of the Krauss-Weber test. The retention time in the test position was recorded in seconds.

Examination of the forced vital capacity was carried out using a Vitalograph Micro Spirometer, Vitalograph 1td, Ireland and the measurement was repeated 3 times, but only the highest score was recorded (Dimitrova et al., 2016; Grigorova-Petrova et al., 2014; Dimitrova et al., 2014). The size of the renal calculi in all patients was between $0.5 \mathrm{~cm}$ to $0.8 \mathrm{~cm}$ in diameter, which enables their sponta- 
neous elimination. Medical ultrasound diagnostics is a noninvasive, accessible method of imaging, especially in establishing X-ray negative calculi. Commonly used are machines with dynamic scanning with transducers $3 \mathrm{MHz}$ and $5 \mathrm{MHz}$ (Vasilev, 1990).

Physical therapy was applied to the patients from both groups during their 15day sanatorium stay. The goals of physical therapy were to improve the renal function and general condition of the patients. For their implementation were the following tasks were set: improving the general blood circulation, improving blood circulation in the kidneys, increasing the micturition, improving and strengthening the peristalsis of the ureters, weight reduction, strengthening abdominal wall muscles, inducing spontaneous migration of the concretions. Physiotherapeutic methods are divided into two parts: physical exercises with overall effect and specific physical exercises. Specific tools included: relaxation exercises, diaphragmatic breathing, running and jumping exercises, strengthening abdominal wall muscles, and emotional mobile games. The pace of implementation was of slow to moderate intensity. In order to avoid sweating of the patients, the level of physical load was mild, and duration of sessions was 30 minutes daily. Physical therapy is divided into three basic periods. The preparatory period is 2-3 days, and it solves the following tasks: to introduce the patients to practicing exercises, to determine of their individual motor capabilities, assess of their functional status (mobility), and to teach some specific exercises. The tools of a complex physiotherapeutic treatment, included in this period, are mainly developing ones, and execises with emotional character. Some specific exercises were given in small doses, such as jumping, shaking, "bear" walking exercise, etc. Moreover, the dosage of these exercises depende $\mathrm{d}$ on the individual health condition of every patient. Special emphasis was placed on proper breathing, especially diaphragmatic breathing. The physiotherpeutic complex in this period mainly consisted of exercises for upper and lower extremities in full range of motion, avoiding strength training and exercises related to exertion. Emotional parts of a complex contained less mobile and semi-mobile games. After the 3rd-4th day, the main period of treatment with physical therapy began. While in the preparatory period, special exercises occupied about $20 \%-25 \%$ of a whole complex, in a main period were included more complex and specialized exercises: stretching of the abdominal and chest muscles from different starting positions, mixed and free hanging of Swedish wall. The dosage of special exercises gradually increased to "bear" walking, shaking, jumping, exercises for lumbar region, flexion and extension of the lower limbs, trunk and pelvis combined with breathing exercises. During this period, the special exercises occupied $50 \%$ of the volume of the session. In order to avoid overload of the patients, which, relaxation exercises were generally given after jumps. This lead to an increas in muscle spasm around the ureters. Upon completion of the treatment course in the sanatorium (final period) a non-supervised rehabilitation program at home was recommended, as special exercises must occupy $25-35 \%$ of the daily session. Both groups took participation in tourist hikes 
with duration of 2-3 hours depending on their condition.

In addition, for the patients of EG, swimming was always carried out after the physiotherapy, so that they used the relaxing effect of the mineral water on the muscles. Swimming was performed twice daily, for $15 \mathrm{~min}$, without rests, freestyle, slow pace.

Statistical analysis was performed with the use SPSS 19 for Windows. Independent and paired sample $t$ tests were conducted to determine effect of intervention. Statistical significance was set at $p<0,05$.

\section{RESULTS}

The changes in the body weight in response to the treatment are presented in Table 1.

Table 1. Changes in the mean values and standard deviations of body weight in the two study groups before and after treatment

\begin{tabular}{cccccc}
\hline Parameter & Group & mean value \pm SD & mean value \pm SD & Difference $(\mathbf{X 2}-\mathbf{X 1})$ & P \\
\hline $\begin{array}{c}\text { Body } \\
\text { weight }(\mathbf{k g})\end{array}$ & EG & $67.35 \pm 10.06$ & $66.30 \pm 9.92$ & -1.05 & $\mathbf{0 . 0 0 1}$ \\
& CG & $77.71 \pm 8.38$ & $77.39 \pm 8.60$ & -0.32 & 0.059 \\
& $\mathbf{p}$ & $\mathbf{0 . 0 0 1}$ & $\mathbf{0 . 0 0 1}$ & & \\
\hline
\end{tabular}

EG-experimental group; CG-control group; SD - standard deviation;P-significant difference compared with values before treatment for each group (Student $t$-test); p-significant difference between the EG and CG (Student t-test)

Before the start of the treatment, the patients of the EG had a lower body weight $(p<0.001)$ compared to the control group. At the end of the treatment the reduction of the body weight with 1.05 $\mathrm{kg}$ was statistically significant $(\mathrm{p}<0.001)$ compared to the minimal changes of only
$0.32 \mathrm{~kg}$ found in the $\mathrm{CG}$.

The changes in the forced vital capacity are shown in Table 2. Statistically significant $(\mathrm{p}<0.001)$ higher forced vial capacity was found in the EG after treatment and no changes were registered in the $\mathrm{CG}$.

Table 2. Changes in the forced vital capacity (mean value and standard deviation) in the experimental and control groups before and after treatment.

\begin{tabular}{cccccc}
\hline Parameter & Group & mean value \pm SD & mean value \pm SD & Difference $(\mathbf{X} 2-\mathbf{X 1})$ & P \\
\hline \multirow{2}{*}{ FVC $(\mathbf{l})$} & EG & $3,25 \pm 0,6$ & $3,38 \pm 0,6$ & 0,13 & $\mathbf{0 . 0 0 1}$ \\
& CG & $3,15 \pm 0,6$ & $3,18 \pm 0,6$ & 0,03 & $>0.05$ \\
\hline
\end{tabular}

FVC - Forced vital capacity; EG-experimental group; CG-control group;SD - standard deviation;Psignificant difference compared with values before treatment for each group(Student $t$-test); p-significant difference between the EG and CG (Student t-test) 
The changes in the abdominal muscles strength are presented in Table 3. There are no significant differences in this indicator between the two groups at the start and at the end of the study.

Significant improvement $(\mathrm{p}<0.001)$

Table 3. Changes in the abdominal muscle strength (mean value and standard deviation) in the experimental and control groups before and after treatment.

\begin{tabular}{cccccc}
\hline Parameter & Group & mean value \pm SD & mean value \pm SD & Difference $($ X2-X1) & P \\
\hline Abdominal & EG & $25.10 \pm 11.48$ & $28.65 \pm 12.60$ & 3.55 & $\mathbf{0 . 0 0 1}$ \\
muscle & CG & $30.43 \pm 15.07$ & $31.96 \pm 15.74$ & 1.54 & $\mathbf{0 . 0 0 1}$ \\
strength & p & 0.191 & 0.434 & & \\
(sec) & & & & \\
\hline
\end{tabular}

EG-experimental group; CG-control group; $S D$ - standard deviation;P-significant difference compared with values before treatment for each group (Student $t$-test);p-significant difference between the EG and CG (Student t-test)

Data regarding spontaneous elimination of the renal concretion, confirmed by ultrasonography and anamnesis, was found in $50 \%(\mathrm{n}=10)$ of the patients from EG and in $28 \%(n=7)$ of the patients from $C G$.

\section{DISCUSSION}

We were interested in monitoring the changes in body weight of the patients, as above-average weight is one of the etiological factors for the nephrolithiasis. Physical inactivity is common among stone clinic patients and lifestyle interventions is crucial for effective prevention (Soueidan, 2015). We believe that the positive change in body weight in both groups can be attributed to increased daily physical activity and ongoing diet. Thus, we can effectively combat obesity and sedentary lifestyle, which is typical of most of the patients and worsens their prognosis (Grigorova-Petrova et al., 2015).

The usual daily physical activity in the sanatorium environment also has a positive impact, but the combination of swimming, physical therapy and SPA potentiates the effect and leads to better results (Lubenova, 2014; Tasheva, 2007).

Changes were monitored in the forced was observed in the abdominal muscle strength in all patients. The improvement was more noticeable in the EG (3.55 sec vs $1.54 \mathrm{sec})$ when compared with the values before treatme nt. vital capacity of the patients. Improving respiratory function and general blood circulation respectively results in an improvement of the renal blood circulation. The presented results give us reason to link the application of focused breathing exercises and swimming at experimental group with the clear result on forced vital capacity among these patients (Dimitrova et al., 2007; Grigorova-Petrova et al., 2014).

Contractions of the abdominal muscles have mechanical effect on the ureteral peristalsis, which can be achieve with purposeful physical exercises on the abdominal wall, which would assist the spontaneous ejection of the stone. It is noteworthy to point out the low starting values of the contraction time of the abdominal muscles of the experimental group - $25.1 \mathrm{sec}$. and of the patients from the control group $30.43 \mathrm{sec}$ which is associated with low daily activity among these patients. These changes give us reason to assert that the exercises for abdominal muscles combined with swimming among EG patients are suitable, but a more prolonged period of time is likely to be needed for a more marked change. 
Positive results of the renal calculi elimination, objectified by ultrasound examination among the patients from the experimental group, compared to the patients from the control group, is likely due to additive effect of swimming that further stimulates the general blood circulation and increases urine output. In turn, releasing of much urine leads to mechanical movement of concretion in the ureters and their elimination.

\section{CONCLUSION}

The results of the present study revealed that the implementation of swimming protocol of two short daily sessions has an additive positive effect to physiotherapy and enhances the outcomes of balneological treatment among patients with nephrolithiasis.

\section{REFERENCES}

Dimitrova, A., Lubenova, D., Grigorova-Petrova, Kr., Maznev, I., Nikolova, M. (2016), The effectiveness of long term physical therapy in elderly patients with chronic obstructive pulmonary disease, European Respiratory Journal, Vol. 48 Suppl. 60, PA 684.

Dimitrova, A., Lubenova, D., Grigorova-Petrova, Kr., Beizat A. (2014), Study on the effect of kinesitherapy on motor activity in patients with Parkinson's disease. In: Congress Proceedings. Sport, Stress, Adaptation, Scientific Journal, Extra Issue, pp. 633-639.

Dimitrova, A., Lyubenova, D., Stefanova, D., Grigorova-Petrova, K. (2007), Kratkosrochna kineziterapevtichna programa pri bolni s khronichna obstruktivna belodrobna bolest, Sborniks dokladi ot XIV Balkanski kongres po sportna meditsina.
Albena: 21-24 septemvri 2006. Prilozhenie kŭm Sport i nauka, Vol. 1, pp. 51-159.

Grigorova-Petrova, K., Dimitrova, A., Lubenova, D., Zaharieva, D., Vasileva, D. (2015), Feasibility of interactive video games for influence on balance in institutionalized elderly people. Journal of Physical Education and Sport, Vol. 15 No. 31, pp. $429-432$.

Grigorova-Petrova, K., Lubenova, D., Dimitrova, A., Baldaranov, D., Lozeva, J. (2014), Feasibility of Early Physical Therapy Program In-Hospital Patients with Acute Ischemic Stroke, Macedonian Journal of Medical Sciences, Vol 7 No.3, pp. 452-455.

Grigorova-Petrova, Kr., Lubenova, D., Dimitrova, A. (2014), Pulmonary function - possibility of influence for in-hospital acute stroke patients, Sport, Stress, Adaptation, Scientific Journal, Extra Issue, pp. 640-643.

Lubenova, D. (2014), Influence of hydrokinesitherapy in the treatment of lumbar disc disease in the chronic period. In: Congress Proceedings. Sport, Stress, Adaptation. Scientific Journal. Extra Issue, pp. 629-632.

Soueidan, M., Bartlett, S., Noureldin, Y. (2015), Leisure time physical activity, smoking and risk of recent symptomatic urolithiasis: Survey of stone clinic patients, Can Urol Assoc J, Vol 9, pp. 257-62.

Tasheva, R. (2007), SPA\&wellness -sŭshtnost i prilozhenie, Meditsina $i$ sport, Vol 1, pp. 16-20.

Vasilev, T. (1990), Klinichna nefrologiya, Meditsina i Fizkultura, Sofiya.

\section{Correspondence:}

Milena Nikolova

National Sports Academy, Sofia, Bulgaria Department of Physiotherapy and Rehabilitation

Email: milenanikolova78@gmail.com 